\title{
Prioritas konservasi lahan dan arahan programnya di Kelurahan Minas Jaya Provinsi Riau
}

\author{
Eno Suwarno*, Hadinoto, dan Muhammad Ikhwan
}

Fakultas Kehutanan, Universitas Lancang Kuning

*enosuwarno@unilak.ac.id

\begin{abstract}
Minas Jaya is one of the villages adjacent to Sultan Syarif Hasyim Forest Park (Tahura SSH). Tahura SSH is one of the conservation areas in Riau Province which is currently in critical condition due to forest encroachment, illegal logging, forest fires and illegal land conversion. In order to restore it requires an approach that combines conservation and community empowerment. One is the concept of Conservation Village. The initial stage in Conservation Village development needs to be a priority class map of conservation. The problems faced by partners to produce such maps require special expertise in spatial planning, mapping, and understanding of conservation village concepts. Based on the mapping identification showing that data of the conservation priority area 1, were identified it consisted of 243.92 hectares, then the conservation priority area 2 consisted of 257.87 hectares. Further, the conservation priority area 3 also identified and consisted of 504.28 hectares, moreover the conservation level 4 conservation area around 1,868.57 hectares, and conservation priorities 5 identified around 1,082.79 hectares. Conservation program directives were linked to each priority of conservation classes. It generally includes a good forest covers protection activities, enrich the land with tree crops. Furthermore, critical land rehabilitation with agroforestry patterns has the choice of species and proportion of annual crops and trees adapted to the degree of land criticality and gradient.
\end{abstract}

\begin{abstract}
Abstrak Minas Jaya merupakan salah satu kelurahan yang berbatasan dengan Taman Hutan Raya Sultan Syarif Hasyim (Tahura SSH). Tahura SSH merupakan salah satu kawasan konservasi di Provinsi Riau yang saat ini dalam kondisi kritis akibat perambahan hutan, penebangan liar, kebakaran hutan, dan alih fungsi lahan secara ilegal. Guna memulihkannya diperlukan pendekatan yang memadukan antara konservasi dan pemberdayaan masyarakat. Salah satunya adalah konsep Desa Konservasi. Tahap awal dalam pembangunan Desa Konservasi perlu adanya peta kelas prioritas konservasi. Permasalahan yang dihadapi oleh mitra untuk menghasilkan peta tersebut diperlukan keahlian khusus di bidang perencanaan tata ruang, perpetaan, dan pemahaman terhadap konsep desa konservasi. Berdasarkan hasil identifikasi diperoleh data luas areal prioritas konservasi 1 seluas 1.243,92 hektar, areal prioritas konservasi 2 adalah 257,87 hektar, areal prioritas konservasi 3 seluas 504,28 hektar, areal tingkat prioritas konservasi 4 seluas 1.868,57 hektar, dan areal tingkat prioritas konservasi 5 seluas 1.082,79 hektar. Arahan program konservasi disesuaikan dengan masingmasing kelas prioritas. Secara umum mencakup kegiatan perlindungan tutupan hutan yang masih baik, pengayaan lahan dengan tanaman pohon-pohonan, rehabilitasi lahan kritis dengan pola agroforestry dengan pilihan jenis dan proporsi jenis tanaman tahunan dan tanaman semusim yang disesuaikan dengan tingkat kekritisan lahan dan kelas kelerengan.
\end{abstract}

\section{OPEN ACCESS}

Citation: Suwarno, E., Hadinoto, dan M. Ikhwan. 2018. Prioritas konservasi lahan dan arahan programnya di Kelurahan Minas Jaya Provinsi Riau. Riau Journal of Empowerment 1(1): 11-21 https://doi.org/10.31258/raje.1.1.2

Received: 2018-05-23, Accepted: 2018-07-31 Language: Bahasa Indonesia (id)

Funding: Program pengabdian kepada masyarakat ini didanai oleh Direktorat Penguatan Riset dan Pengabdian Kepada Masyarakat Kementerian Riset, Teknologi, dan Pendidikan Tinggi sesuai kontrak nomor 112/K10/KM/Kontrak/Pengabmas/2018

C 2018 Suwarno et al. The article by Author(s) is licensed under a Creative Commons Attribution 4.0 International License. This license permits unrestricted use, distribution, and reproduction in any medium, provided the original author and source are credited. 
Keywords: Tahura SSH; spatial; conservation village; agroforestry

\section{PENDAHULUAN}

Kelurahan Minas Jaya Kecamatan Minas Kabupaten Siak merupakan salah satu kelurahan yang wilayahnya berbatasan langsung dengan kawasan konservasi Taman Hutan Raya Sultan Syarif Hasyim (Tahura SSH). Kondisi kawasan konservasi Tahura SSH II saat ini tengah mengalami degradasi dan deforestasi yang parah. Berdasarkan informasi dari pengelola KPHP Minas Tahura sebagian besar wilayahnya sudah berubah menjadi kebun kelapa sawit dan sebagian berupa lahan kritis. Berdasarkan Surat Keputusan Menteri Kehutanan Nomor 348/KPTS/II/1999, luas kawasan konservasi Tahura SSH II 6.172 hektar, namun saat ini luas tutupan hutannya tinggal 2.087 hektar [6]. Dengan kata lain telah terjadi degradasi dan deforestasi sekitar dua pertiga dari luas total kawasan konservasi tersebut. Menurut Dev Roy [4], masyarakat yang tinggal dekat kawasan konservasi melakukan akses secara ilegal terhadap hutan karena kurangnya peluang ekonomi alternatif. Menurut Allnutt et al. [1] dan Michinaka et al. [7] menyatakan bahwa kepadatan penduduk memberikan dampak yang negatif sebagai pemicu deforestasi. Di negara-negara berkembang seperti Indonesia, deforestasi memang banyak disebabkan oleh faktor-faktor sosial, ekonomi, dan budaya [7, 3].

Berdasarkan fakta lapangan tersebut maka perlu dilakukan upaya-upaya penyelamatan kawasan konservasi dan memperbaiki kualitas lingkungan dalam skala yang massif. Atas dasar keprihatinan ini maka tim Ipteks bagi Masyarakat (IbM) Universitas Lancang Kuning melakukan komunikasi dengan beberapa unsur masyarakat dan aparatur Kelurahan Minas Jaya untuk menawarkan program Desa Konservasi. Dari hasil komunikasi tersebut ternyata baik unsur masyarakat maupun aparatur Kelurahan menyambut baik gagasan pembentukan Desa Konservasi dan menyatakan siap untuk melaksanakannya di Kelurahan Minas Jaya.

Berdasarkan pengalaman pelaksanaan program desa koservasi di desa sekitar Taman Nasional Bukit Barisan Selatan Selatan, Ristianasari dkk [9] melaporkan bahwa pemberdayaan masyarakat melalui model desa konservasi cenderung mengurangi aktivitas masyarakat untuk merusak hutan. Demikian juga Suhendri [12] dalam penelitiannya di Taman Nasional Gunung Palung, Kalimantan Barat. Dengan kata lain Sarkar [11] dan Dev Roy [4] menyatakan bahwa masyarakat lebih berorientasi pada konservasi apabila disediakan peluang penghidupan alternatif.

Sebagai tahap awal pembentukan desa konservasi diperlukan peta tata ruang desa berbasiskan konservasi. Dengan adanya peta tata ruang ini dimaksudkan agar pembangunan desa bisa lebih terarah dan teratur [10]. Menurut Tisnaamidjaja dalam Yusuf [14], ruang adalah wujud fisik wilayah dalam dimensi geografis dan geometris yang merupakan wadah bagi manusia dalam melaksanakan kegiatan kehidupannya dalam suatu kualitas kehidupan yang layak.

\section{MASALAH}

Mitra dari kegiatan IbM ini adalah pimpinan aparatur kelurahan dan beberapa tokoh masyarakat Kelurahan Minas Jaya yang memiliki kepedulian terhadap penyelamatan dan perbaikan kualitas lingkungan. Dalam rangka mewujudkan desa konservasi, permasalahan yang dihadapi oleh mitra cukup banyak, mulai dari tahap perencanaan hingga tahap pelaksanaan. Namun untuk tahap awal yang disepakati adalah perlu dibuatnya peta kelas prioritas konservasi Kelurahan Minas Jaya. Universitas Lancang Kuning telah menetapkan Kelurahan Minas Jaya sebagai salah satu desa binaan. Dengan adanya permasalahan di atas, maka tim IbM Universitas Lancang Kuning memiliki komitmen untuk ikut membantu menyelesaikan permasalahan mitra dengan mendayagunakan keahlian dan pengalaman yang dimiliki oleh Tim IbM.

\section{METODE PELAKSANAAN}


Mengacu kepada Safitri dkk [10], tahapan penyusunan rencana tata ruang desa secara partisipatif adalah sebagai berikut:

I. Tahapan Persiapan dan Pengumpulan Data Lapangan

a. Mobilisasi tenaga ahli yang akan diperbantukan dan identifikasi semua perwakilan masyarakat yang akan diundang

b. Survey primer dan survai sekunder untuk mengetahui kondisi di lapangan dan mengumpulkan data desa 5 tahun ke belakang secara time series oleh tenaga ahli yang diperbantukan bersama aparat desa.

c. Melakukan Focus Group Discussion (FGD) dan Jaring Aspirasi Masyarakat (Jasmara), meliputi materi potensi, masalah, harapan, dan ancaman di lapangan, kebutuhan dan keinginan masyarakat dalam pembangunan.

d. Melakukan pemetaan lapangan bersama masyarakat.

e. Melakukan kompilasi data oleh tenaga ahli.

II. Tahapan Analisa

a. Melakukan analisa di semua sektor pembangunan, meliputi analisis kebijakan, analisis kedudukan regional desa (internal dan eksternal), analisis fisik (daya dukung dan daya tampung), analisis demografi kependudukan, analisis sosial ekonomi budaya, analisis kebutuhan jaringan utilitas dan fasilitas, analisis jaringan transportasi, analisis kelembagaan, analisis partisipasi, analisis SWOT.

b. Menyusun konsep pengembangan desa.

c. FGD dengan masyarakat.

d. Melakukan perbaikan dan menggabungan hasil FGD dengan Analisa.

III. Tahapan Rencana

a. Menyusun draft rencana tata ruang desa.

b. FGD dengan masyarakat hasil draft rencana.

c. Perbaikan laporan menjadi Rencana Tata Ruang Desa.

d. Menyusun Rancangan Peraturan Gubernur tentang Rencana Tata Ruang Desa.

IV. Tahapan Pengesahan Rencana Tata Ruang Desa

a. Pembahasan Rancangan Peraturan Gubernur tentang Rencana Tata Ruang Desa terkait.

b. Perbaikan Rancangan Peraturan Desa dan Peraturan Gubernur.

Namun lingkup kegiatan yang dilaksanakan dalam kegiatan IbM ini dibatasi hanya sampai kepada tahap satu, yaitu Tahapan Persiapan dan Pengumpulan Data Lapangan, dimana hasilnya berupa Peta tingkat prioritas konservasi lahan di wilayah Kelurahan Minas Jaya disertai arahan programnya.

\section{HASIL DAN PEMBAHASAN}

\section{Gambaran Umum Lokasi}

Kelurahan Minas Jaya merupakan salah satu kelurahan yang ada di kecamatan Minas, Kabupaten Siak, Provinsi Riau. Kelurahan Minas Jaya ditetapkan melalui Peraturan Daerah Kabupaten Siak Nomor 39 Tahun 2002, tanggal 20 September 2002. Memiliki luas wilayah sekitar 4.957,43 Ha. Sebelah Utara berbatasan dengan Desa Minas Barat, sebelah Selatan berbatasan dengan Kelurahan Muara Fajar, sebelah Barat berbatasan dengan Desa Minas Timur, dan sebelah Timur berbatasan dengan Desa Rantau Bertuah. Pada tahun 2016 jumlah penduduknya 13.887 orang, terdiri dari laki-laki 7.127 orang, dan perempeuan 6.760 orang [2]. Dengan demikian kepadatan penduduknya sekitar 280 jiwa per kilometer persegi. Sampai saat ini Kelurahan Minas Jaya belum memiliki dokumen rencana tata ruang kelurahan.

Luas wilayah Kelurahan Minas Jaya berdasarkan penggunaan lahan sebagaimana ditampilkan pada Tabel 1. 
Tabel 1. Luas Wilayah Kelurahan Minas Jaya Berdasarkan Penggunaan Lahan

\begin{tabular}{clrclr}
\hline No & Penggunaan Lahan & Luas (Ha) & No & Penggunaan Lahan & Luas (Ha) \\
\hline 1 & Pemukiman & 970,45 & 6 & Taman & 25,82 \\
2 & Persawahan & 0,00 ha & 7 & Perkantoran & 114,23 \\
3 & Perkebunan & $1.802,83$ & 8 & Prasarana umum & 379,27 \\
4 & Pekuburan & 5,00 & 9 & Hutan Lindung & $1.243,92$ \\
5 & Pekarangan & 415,91 & & Luas total & $4.957,43$
\end{tabular}

Sumber: Diolah dari Kecamatan Minas Dalam Angka 2017 [2] dan Peta Kelurahan Minas Jaya

Kondisi penggunaan lahan saat ini didominasi oleh perkebunan, terutama perkebunan kelapa sawit masyarakat. Dahulunya masyarakat membuka hutan alam yang kemudian dikonversi menjadi kebun kelapa sawit. Di wilayah Kelurahan Minas Jaya juga masih terdapat hutan lindung seluas 1243,92 hektar. Hutan lindung tersebut adalah kawasan konservasi Taman Hutan Raya Sultan Syarif Hasyim. Salah satu fungsi kawasan lindung terutama dalam rangka melindungi sumber air. Sumber air yang berada di Kelurahan Minas Jaya berupa waduk bendungan PDAM untuk sumber air yang didistribusikan bagi masyarakat di seluruh Kecamatan Minas.

\section{Pengecekan Lapangan}

Pengecekan lapangan (ground-check) bertujuan untuk melihat dan mengetahui kondisi fisik lapangan (kondisi tutupan lahan, topografi, sebaran badan air, lahan kritis, dan lain-lain), serta mengambil titik-titik koordinat dengan menggunakan alat GPS. Pengecekan lapangan dilakukan di beberapa tempat, antara lain di kawasan lindung Taman Hutan Raya Sultan Syarif Hasyim, di dekat waduk PDAM, di kebun masyarakat, di lokasi program agroforestri, di kebun kelapa sawit masyarakat, dan di lahan kritis menuju ke Pusat Latihan Gajah (PLG).

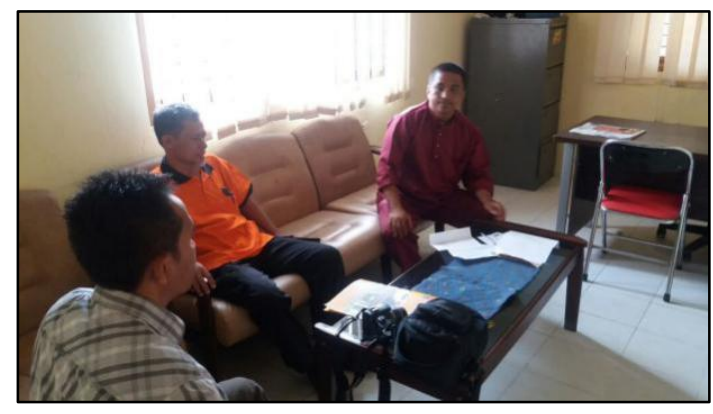

Gambar 1. Diskusi dengan Sekretaris Lurah

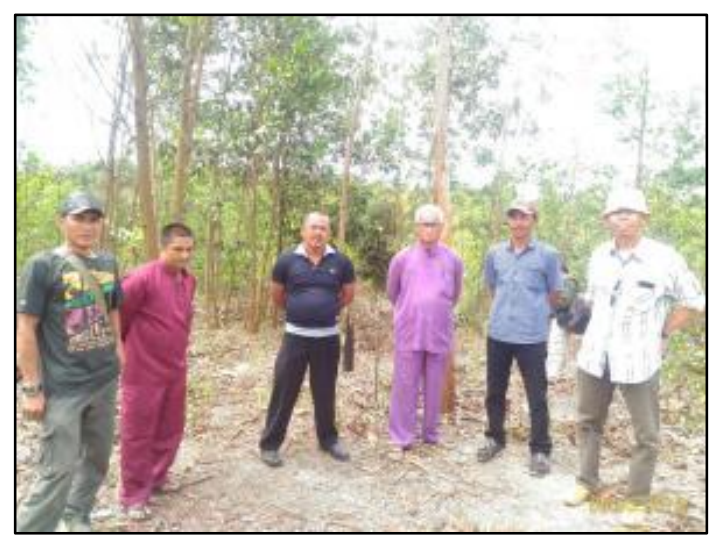

Gambar 2. Pengecekan lapangan dengan Sekretaris lurah dan rom 


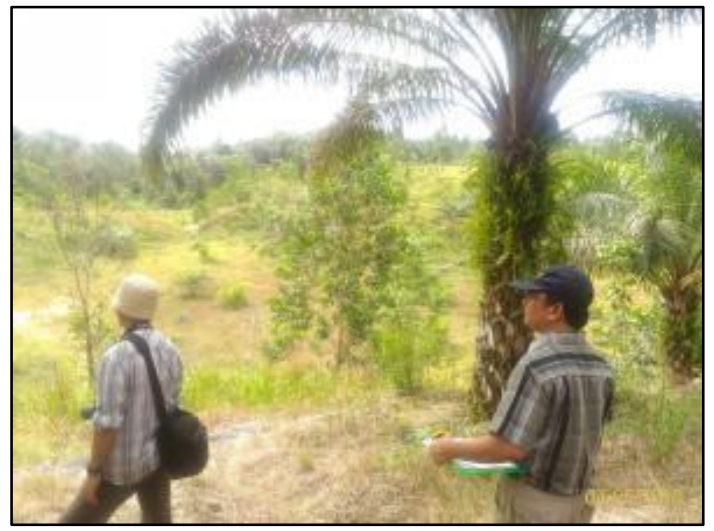

Suwarno dkk.

Gambar 3. Mengambil titik koordinat di daerah bendungan \& batas Tahura SSH II

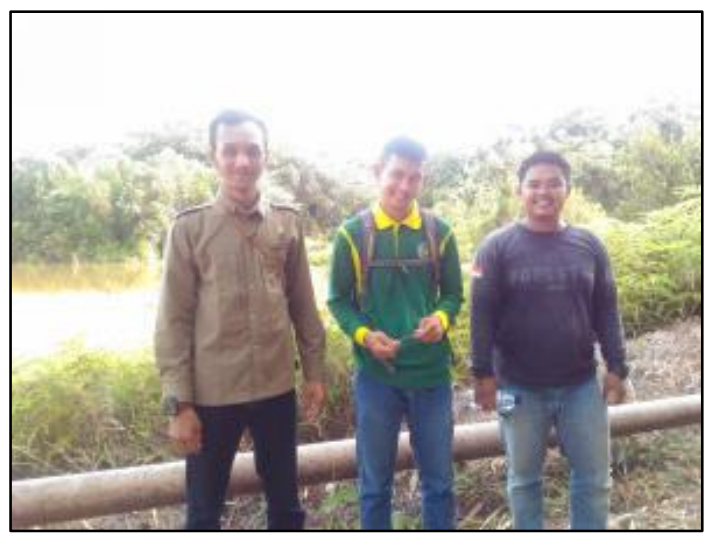

Gambar 4. Pelibatan mahasiswa Fakultas Kehutanan Unilak dalam kegiatan pengabdian

\section{Pembuatan Peta}

Pembuatan peta tata ruang wilayah kelurahan Minas Jaya berdasarkan konsep Desa Konservasi, disusun berdasarkan peta sebaran lahan kritis, peta jaringan sungai, peta kelas kelerengan lahan, peta status kawasan, dan peta penggunaan lahan. Produk akhirnya berupa peta tata ruang yang memberi arahan kelas-kelas prioritas konservasi lahan berdasarkan urgensi Daerah Aliran Sungai (DAS) sebagai salah satu unsur daya dukung lingkungan pokok bagi kehidupan umat manusia.

Peta status kawasan memberikan batas-batas dimana areal yang termasuk kawasan hutan dan dimana areal yang bukan kawasan hutan. Di Kelurahan Minas Jaya yang termasuk ke dalam kawasan hutan adalah kawasan lindung Tahura SSH, sedangkan selain itu termasuk ke dalam areal penggunaan lain (APL). Peta penggunaan lahan berguna untuk memberikan arahan jenis kegiatan konservasi. Adapun peta sebaran lahan kritis, peta jaringan sungai, peta kelas lereng digunakan sebagai kriteria dalam menentukan kelas-kelas prioritas konservasi lahan. Berdasarkan hasil tumpang susun (overlay) bahan-bahan tersebut maka dihasilkan hasil akhir berupa peta tingkat prioritas konservasi lahan Kelurahan Minas Jaya sebagaimana Gambar 5. 


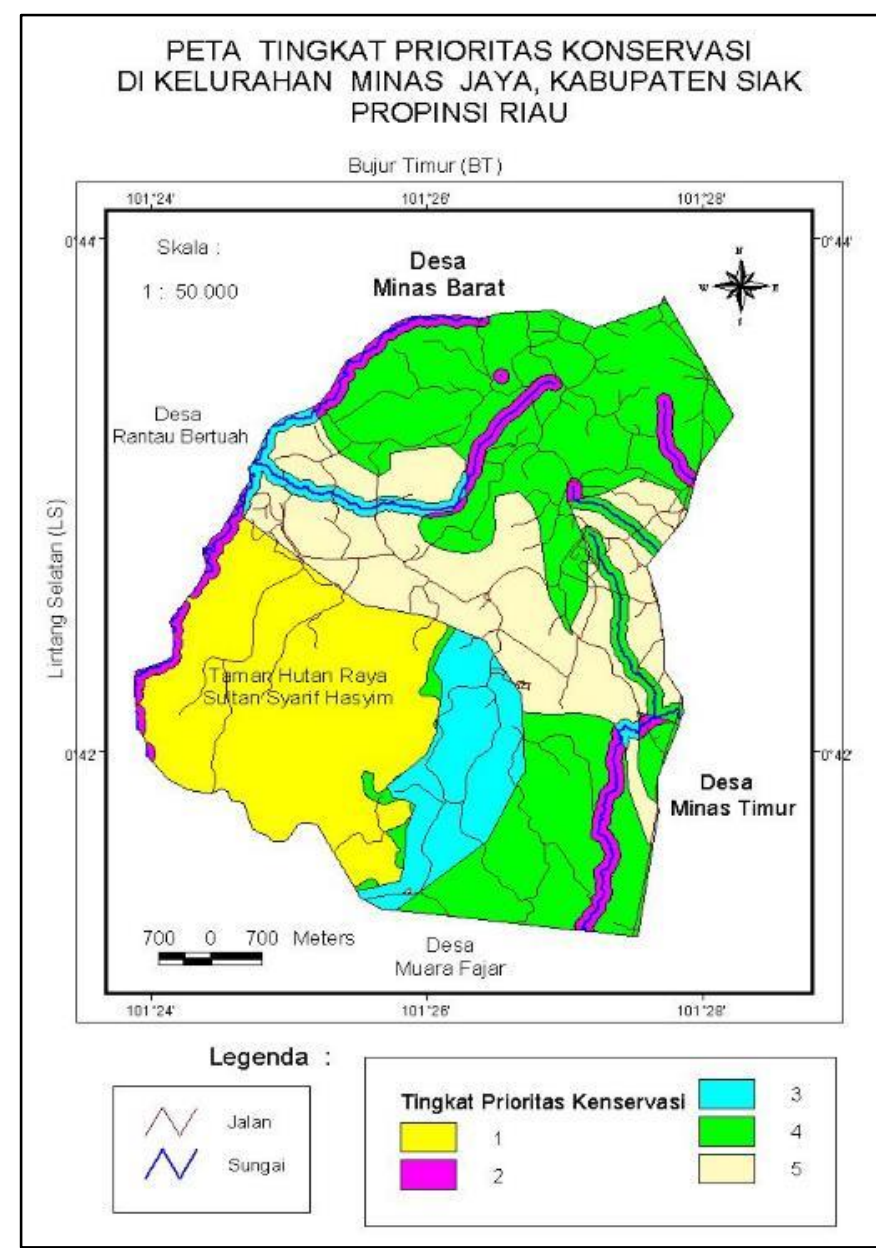

Gambar 5. Peta Tingkat Prioritas Konservasi Lahan Kelurahan Minas Jaya Tabel 2.

Luas areal pada masing-masing kelas prioritas konservasi sebagaimana ditampilkan pada

Tabel 2. Kelas Prioritas Konservasi Lahan Kelurahan Minas Jaya

\begin{tabular}{|c|c|c|}
\hline $\begin{array}{c}\text { Kelas } \\
\text { prioritas }\end{array}$ & Kriteria lahan & Luas (ha) \\
\hline 1 & $\begin{array}{l}\text { a. Kawasan Konservasi TAHURA } \\
\text { b. Lahan Kritis, Kelas lereng 3, Jarak dari sungai } 100 \mathrm{~m}\end{array}$ & $1.243,92$ \\
\hline 2 & $\begin{array}{l}\text { a. Lahan Kritis, Kelas lereng 2, Jarak dari sungai } 100 \mathrm{~m} \\
\text { b. Lahan Agak Kritis, Kelas lereng 3, Jarak dari sungai } \\
100 \mathrm{~m}\end{array}$ & 257,87 \\
\hline 3 & $\begin{array}{l}\text { a. Lahan Agak Kritis, Kelas lereng 2, Jarak dari sungai } \\
100 \mathrm{~m} \\
\text { b. Lahan Potensial Kritis, Kelas lereng 3, Jarak dari } \\
\text { sungai } 100 \mathrm{~m}\end{array}$ & 504,28 \\
\hline 4 & $\begin{array}{l}\text { a. Lahan Kritis, Kelas lereng 2, Jarak dari sungai lebih } \\
100 \mathrm{~m} \\
\text { b. Lahan Potensial Kritis, Kelas lereng 2, Jarak dari } \\
\text { sungai } 100 \mathrm{~m} \\
\text { c. Lahan Kritis, Kelas lereng 3, Jarak dari sungai lebih } \\
100 \mathrm{~m}\end{array}$ & $1.868,57$ \\
\hline
\end{tabular}




\begin{tabular}{|c|c|c|}
\hline $\begin{array}{c}\text { Kelas } \\
\text { prioritas }\end{array}$ & Kriteria lahan & Luas (ha) \\
\hline \multirow[t]{9}{*}{5} & $\begin{array}{l}\text { a. Lahan Tidak Kritis, Kelas lereng 2, Jarak dari sungai } \\
\text { lebih } 100 \mathrm{~m}\end{array}$ & $1.082,79$ \\
\hline & $\begin{array}{l}\text { b. Lahan Tidak Kritis, Kelas lereng 3, Jarak dari sungai } \\
\text { lebih } 100 \mathrm{~m}\end{array}$ & \\
\hline & $\begin{array}{l}\text { c. Lahan Potensial Kritis, Kelas lereng 2, Jarak dari } \\
\text { sungai lebih } 100 \mathrm{~m}\end{array}$ & \\
\hline & $\begin{array}{l}\text { d. Lahan Tidak Kritis, Kelas lereng 2, Jarak dari sungai } \\
100 \mathrm{~m}\end{array}$ & \\
\hline & $\begin{array}{l}\text { e. Lahan Agak Kritis, Kelas lereng 3, Jarak dari sungai } \\
\text { lebih } 100 \mathrm{~m}\end{array}$ & \\
\hline & $\begin{array}{l}\text { f. Lahan Agak Kritis, Kelas lereng 2, Jarak dari sungai } \\
\text { lebih } 100 \mathrm{~m}\end{array}$ & \\
\hline & $\begin{array}{l}\text { g. Lahan Potensial Kritis, Kelas lereng 3, Jarak dari } \\
\text { sungai lebih } 100 \mathrm{~m}\end{array}$ & \\
\hline & $\begin{array}{l}\text { h. Lahan Tidak Kritis, Kelas lereng 3, Jarak dari sungai } \\
100 \mathrm{~m} \text {. }\end{array}$ & \\
\hline & Jumlah & $4.957,43$ \\
\hline
\end{tabular}

Berdasarkan perbedaan warna pada peta (Gambar 5) kita dapat mengetahui sebaran areal berdasarkan kelas prioritas konservasi. Areal yang diberi warna kuning menunjukan tingkat prioritas konservasi 1 . Semuanya berada pada kawasan lindung Tahura SSH dengan luas 1.243,92 hektar. Kawasan tersebut telah ditetapkan oleh pemerintah sebagai kawasan konservasi. Fungsi utama Tahura sebagai kawasan pelestarian alam (KPA) adalah untuk melestarikan keanekaragam hayati dan ekosistemnya. Selain itu keberadaan Tahura juga memiliki multi fungsi sebagai penyangga kehidupan, terutama untuk tata air yang sangat dibutuhkan oleh manusia.

Selanjutnya areal yang diberi warna ungu menunjukkan tingkat prioritas konservasi 2 . Dibanding dengan areal yang lainnya, luas areal prioritas 2 paling sedikit, yaitu 257,87 hektar. Sebagaimana dapat dilihat di peta, sebaran areal prioritas 2 pada umumnya mengikuti badan sungai. Kondisi di lapangan adalah berupa lahan kritis atau lahan agak kritis dengan jarak 100 m kiri kanan badan sungai.

Selanjutnya areal yang diberi warna biru muda menunjukkan tingkat prioritas konservasi 3. Dibanding dengan areal yang lainnya, luas areal prioritas 3 ada pada urutan nomor dua paling sedikit, yaitu 504,28 hektar. Sebagaimana terlihat di peta, sebaran areal prioritas 3 ada pada tiga lokasi, Dua lokasi ada pada kiri kanan badan sungai, dan satu lokasi lagi berbatasan dengan kawasan konservasi Tahura. Areal dengan tingkat prioritas konservasi 3, kondisi di lapangannya adalah berupa lahan agak kritis atau lahan potensial kritis dengan jarak $100 \mathrm{~m}$ kiri kanan badan sungai.

Selanjutnya areal yang diberi warna hijau menunjukkan tingkat prioritas konservasi 4 . Dibanding dengan areal yang lainnya, luas areal prioritas 4 adalah yang paling luas, yaitu seluas 1.868,57 hektar. Sebagaimana terlihat di peta, sebaran areal prioritas 4 sebagian kecil ada pada kiri kanan badan sungai dan berbatasan dengan kawasan konservasi Tahura, sedangkan sebagian besar lagi berada di lokasi lainnya. Kondisi di lapangannya dapat berupa lahan kritis, kelas lereng 2, dan jarak dari sungai lebih 100 m; lahan potensial kritis, kelas lereng 2, dan jarak dari sungai $100 \mathrm{~m}$; atau lahan kritis, kelas lereng 3, dan jarak dari sungai lebih $100 \mathrm{~m}$.

Terakhir areal yang diberi warna coklat muda menunjukkan tingkat prioritas konservasi 5. Dibanding dengan areal yang lainnya, luas areal prioritas 5 adalah ketiga terluas, yaitu seluas $1.082,79$ hektar. Sebagaimana terlihat di peta, sebaran areal prioritas 5 tidak mempunya pola 
yang khusus. Kondisi di lapangannya umumnya berupa kombinasi dari lahan agak kritis hingga tidak kritis, kelas lereng 2 dan 3, dan jarak dari sungai $100 \mathrm{~m}$ atau lebih.

\section{Arahan Program Konservasi}

Menurut Wahyudi [13], konservasi tanah dan air mengandung pengertian bagaimana penggunaan tanah agar dapat memberi manfaat yang optimum bagi kepentingan umat manusia dalam jangka waktu yang berkelanjutan. Kegiatan konservasi tanah meliputi pengendalian erosi, banjir, pengaturan pemanfaatan air, peningkatan daya guna lahan, peningkatan produksi dan pendapatan petani termasuk peningkatan peran serta masyarakat yang terpadu dan kegiatan pengamanannya.

Kegiatan konservasi dapat menggunakan metode mekanis atau teknik sipil, seperti pembuatan teras sering, bangunan pengendali, bangunan penahan sedimen dan erosi dan lainlain dan metode vegetatif, yaitu dengan penanaman pohon dan tanaman penutup tanah $[13,5]$. Tahapan pelaksanaan kegiatan konservasi meliputi perencanaan, pelaksanaan, bimbingan teknis pelaksanaan, pemeliharaan, monitoring dan penyuluhan pada masyarakat [13].

Arahan program konservasi disesuaikan dengan masing-masing kelas prioritas konservasi. Untuk prioritas konservasi 1, dimana semua arealnya berada di kawasan lindung Tahura SSH dengan luas 1.243,92 hektar, maka arahan programnya adalah: (1) Pada lahan yang masih baik tutupan hutannya, maka program utama adalah perlindungan hutan, terutama dari gangguan pengrusakan oleh manusia. Hutan alami biasanya memiliki kerapatan pohon dan serasah yang tinggi sehingga dapat mengurangi daya rusak air hujan terhadap tanah dan mengurangi laju aliran permukaan. Program perlidungan hutan seyogianya dilakukan secara bersama antara pengelola kawasan lindung tersebut, pemerintah kelurahan, dan masyarakat; (2) Bila pada kawasan lindung terdapat lahan kritis atau tutupan hutannya sudah terdegradasi, pada prinsipnya harus dilakukan upaya pemulihan ekosistem. Di dalam pelaksanaaannya dapat dirancang program pemulihan ekosistem dengan mengkombinasikan dua kepentingan sekaligus, yaitu kepentingan ekologis dan kepentingan pemberdayaan masyarakat. Pola yang lazim guna memenuhi dua kepentingan ini adalah pola agroforestry.

Menurut Pasya dkk [8], proporsi jenis dan jumlah tanaman pangan disesuaikan dengan kemiringan lahan. Sebagai acuan umumnya proporsi tanaman pada lahan dengan kemiringan yang berbeda, yaitu pada kelerengan $<15 \%$ proporsi penanaman $25 \%$ tanaman tahunan dan $75 \%$ tanaman semusim; pada kelerengan $15-30 \%$ proporsi penanaman tanaman tahunan dan semusim adalah sama, yaitu masing-masing 50\%; pada kemiringan lereng 30-40\% proporsi penanaman tanaman tahunan adalah $75 \%$ dan tanaman semusim 25\%; serta untuk kelerengan $>40 \%$ penerapan tanaman adalah tanaman tahunan saja, sebab pada kemiringan ini merupakan kriteria fungsi kawasan lindung.

Luas areal prioritas 2 adalah 257,87 hektar. Sebaran areal prioritas 2 pada umumnya mengikuti badan sungai. Kondisi di lapangan adalah berupa lahan kritis atau lahan agak kritis dengan jarak $100 \mathrm{~m}$ kiri kanan badan sungai. Maka arahan programnya adalah: (1) Pada lahan kritis maupun agak kritis dengan jarak 100 meter kiri kanan badan sungai, dilakukan rehabilitasi dengan cara menanam berbagai jenis pohon-pohonan hutan. Pohon dipilih terutama terutama dari jenis setempat yang cepat tumbuh dan dari kelompok perintis. Penanaman dilakukan dengan jarak tanam yang rapat, yang kemudian dibiarkan tumbuh menjadi hutan kembali; (2) Bila kondisinya berupa kebun masyarakat, maka prinsipnya harus diperkaya dengan berbagai macam jenis pohon-pohonan tahunan, dengan meminimalisir sistem pertanian lahan terbuka; (3) Bila kondisinya berupa lahan pemukiman masyarakat, maka minimal pada areal 5-10 meter badan sungai diperkaya dengan pohon-pohonan, dan dinding sungai sedapat mungkin tertutup dengan semak dan rerumputan.

Areal prioritas 3 seluas 504,28 hektar dimana sebarannya ada pada tiga lokasi, yaitu dua lokasi ada pada kiri kanan badan sungai dan satu lokasi lagi berbatasan dengan kawasan konservasi Tahura. Kondisi di lapangan dapat berupa lahan agak kritis atau lahan potensial kritis dengan jarak 100 m kiri kanan badan sungai. Arahan program pada areal prioritas 3 adalah: (1) Pada lahan agak kritis maupun potensial kritis dengan jarak 100 meter kiri kanan badan sungai, dilakukan rehabilitasi dan pengayaan dengan cara menanam berbagai jenis pohon-pohonan hutan. Pohon dipilih terutama terutama dari jenis setempat, campuran antara 
jenis yang cepat tumbuh dan agak lambat tumbuh; (2) Bila kondisinya berupa kebun masyarakat, maka prinsipnya harus diperkaya dengan berbagai macam jenis pohon-pohonan tahunan, dengan meminimalisir sistem pertanian lahan terbuka; (3) Bila kondisinya berupa lahan pemukiman masyarakat, maka minimal pada areal 5-10 meter badan sungai diperkaya dengan pohon-pohonan, dan dinding sungai sedapat mungkin tertutup dengan semak dan rerumputan.

Selanjutnya areal tingkat prioritas konservasi 4 seluas $1.868,57$ hektar. Sebaran areal prioritas 4 sebagian kecil ada pada kiri kanan badan sungai dan berbatasan dengan kawasan konservasi Tahura, sedangkan sebagian besar lagi berada di lokasi lainnya. Kondisi di lapangannya dapat berupa lahan kritis, kelas lereng 2, dan jarak dari sungai lebih $100 \mathrm{~m}$; lahan potensial kritis, kelas lereng 2, dan jarak dari sungai $100 \mathrm{~m}$; atau lahan kritis, kelas lereng 3, dan jarak dari sungai lebih $100 \mathrm{~m}$. Arahan program pada areal prioritas 4 adalah: (1) Pada lahan agak kritis maupun potensial kritis dengan jarak 100 meter kiri kanan badan sungai, dilakukan rehabilitasi dan pengayaan dengan cara menanam berbagai jenis pohon-pohonan hutan. Pohon dipilih terutama terutama dari jenis setempat, campuran antara jenis yang cepat tumbuh dan agak lambat tumbuh; (2) Bila kondisinya berupa kebun masyarakat, maka prinsipnya harus diperkaya dengan berbagai macam jenis pohon-pohonan tahunan, dengan meminimalisir sistem pertanian lahan terbuka, sehingga terbentuk pola tanam agroforestry; (3) Bila kondisinya berupa lahan pemukiman masyarakat, maka minimal pada areal 5-10 meter badan sungai diperkaya dengan pohon-pohonan, dan dinding sungai sedapat mungkin tertutup dengan semak dan rerumputan.

Terakhir areal tingkat prioritas konservasi 5 seluas 1.082,79 hektar. Areal prioritas 5 tidak mempunya pola sebaran yang khusus. Kondisi di lapangannya umumnya berupa kombinasi dari lahan agak kritis hingga tidak kritis, kelas lereng 2 dan 3, dan jarak dari sungai $100 \mathrm{~m}$ atau lebih. Arahan program yang dapat dilakukan pada areal prioritas 5 adalah: (1) Pada lahan agak kritis, potensial kritis maupun tidak kritis dengan jarak 100 meter kiri kanan badan sungai, dilakukan pengayaan dengan cara menanam berbagai jenis pohon-pohonan hutan, dan melindungi vegetasi yang sudah ada Pohon untuk pengayaan dipilih terutama terutama dari jenis setempat, campuran antara jenis yang cepat tumbuh dan agak lambat tumbuh; (2) Bila kondisinya berupa kebun masyarakat, maka prinsipnya harus diperkaya dengan berbagai macam jenis pohon-pohonan tahunan, dengan meminimalisir sistem pertanian lahan terbuka, sehingga terbentuk pola tanam agroforestry; (3) Bila kondisinya berupa lahan pemukiman masyarakat, maka minimal pada areal 5-10 meter badan sungai diperkaya dengan pohonpohonan, dan dinding sungai sedapat mungkin tertutup dengan semak dan rerumputan.

\section{KESIMPULAN DAN SARAN}

Berdasarkan hasil identifikasi di peta diperoleh data luas areal prioritas konservasi 1 seluas 1.243,92 hektar, semuanya berada di kawasan lindung Tahura SSH. Kemudian luas areal prioritas konservasi 2 adalah 257,87 hektar, dimana hampir semua lokasinya mengikuti badan sungai. Areal prioritas konservasi 3 seluas 504,28 hektar, sebarannya ada pada tiga lokasi yaitu dua lokasi ada pada kiri kanan badan sungai dan satu lokasi lagi berbatasan dengan kawasan konservasi Tahura. Areal tingkat prioritas konservasi 4 seluas 1.868,57 hektar, lokasinya sebagian kecil ada pada kiri kanan badan sungai dan berbatasan dengan kawasan konservasi Tahura, sedangkan sebagian besar lagi berada di lokasi lainnya. Kemudian areal tingkat prioritas konservasi 5 seluas 1.082,79 hektar, dimana lokasinya tidak mempunya pola sebaran yang khusus.

Arahan program konservasi disesuaikan dengan masing-masing kelas prioritas. Secara umum arahan program tersebut mencakup kegiatan perlindungan tutupan hutan yang masih baik, pengayaan lahan dengan tanaman pohon-pohonan, rehabilitasi lahan kritis dengan pola agroforestry dengan pilihan jenis dan proporsi jenis tanaman tahunan dan tanaman semusin yang disesuaikan dengan tingkat kekritisan lahan dan kelas kelerengan. Melalui pola ini diharapkan selain dapat diwujudkan perbaikan kualitas lingkungan, juga diharapkan dapat membantu meningkatkan kesejahteraan masyarakat. 
Hasil akhir kegiatan pengabdian kepada masyarakat ini berupa peta tata ruang wilayah kelurahan berdasarkan kelas prioritas konservasi. Untuk pemanfaatan peta ini disarankan agar ada program pendampingan lebih lanjut kepada aparat pemerintah dan masyarakat Kelurahan Minas Jaya, terutama dalam pelaksanaan program-program konservasi sesuai dengan arahan program di dalam laporan ini.

\section{UCAPAN TERIMA KASIH}

Ucapan terima kasih disampaikan kepada Direktorat Penguatan Riset dan Pengabdian Kepada Masyarakat Kementerian Riset, Teknologi, dan Pendidikan Tinggi yang telah membiayai program pengabdian kepada masyarakat ini melalui dana hibah tahun 2018 sesuai kontrak nomor 112/K10/KM/Kontrak/Pengabmas/2018. Ucapan terima kasih juga disampaikan kepada Universitas Lancang Kuning yang telah memberikan dukungan peralatan dan fasilitas yang diperlukan.

\section{Daftar Pustaka}

1. Allnutt, T.F., G.P. Asner, C.D. Golden, and G.V.N. Powell. 2013. Mapping recent deforestation and forest disturbance in northeastern Madagascar. Tropical Conservation Science 6: 1-15. https://doi.org/10.1177/194008291300600101

2. Badan Pusat Statistik Kabupaten Siak. 2017. Kecamatan Minas dalam Angka 2017. Siak: Badan Pusat Statistik Kabupaten Siak.

3. Banerjee, A., and C. Madhurima. 2013. Forest degradation and livelihood of local communities in India: A human rights approach. Journal of Horticulture and Forestry 5(8): 122-129. https://doi.org/10.5897/JHF2013.0305 online: http://www.academicjournals.org/journal/JHF/article-abstract/488F2773349 Accessed 5 April 2018.

4. Dev Roy, A.K. 2016. Local community attitudes towards mangrove forest conservation: Lessons from Bangladesh. Marine Policy 74: 86-194.

5. Kalsum, U., Y. Yunus, dan T. Ferijal. 2017. Arahan Konservasi DAS Meureudu Menggunakan Sistem Informasi Geografis (SIG). Jurnal Ilmiah Mahasiswa Pertanian Unsyiah 2(2): 423-429. http://jim.unsyiah.ac.id/JFP/article/view/3050. Diakses pada 15 Mei 2018.

6. Kesatuan Pengelolaan Hutan Produksi Model Minas TAHURA. 2015. Rencana Pengelolaan Hutan Jangka Panjang (RPHJP) Kesatuan Pengelolaan Hutan Produksi (KPHP) Model Minas TAHURA Tahun 2015-2025. Pekanbaru: KPHP Minas Tahura.

7. Michinaka, T., M. Miyamoto, Y. Yokota, H. Sokh, S. Lao, and V. Ma. 2013. Factors affecting forest area changes in Cambodia: An econometric approach. Journal of Sustainable Development. https://doi.org/10.5539/jsd.v6n5p12

8. Pasya, G.K., Jupri, dan H. Murtianto. 2009. Tingkat Kerusakan dan Arahan Konservasi Lahan di DAS Cikaro, Kabupaten Bandung. Jurnal Geografi GEA 9(2). https://doi.org/10.17509/gea.v9i2.2452

9. Ristianasari, P. Muljono, dan D.S. Gani. 2013. Dampak Program Pemberdayaan Model Desa Konservasi terhadap Kemandirian Masyarakat: Kasus di Taman Nasional Bukit Barisan Selatan Lampung. Jurnal Penelitian Sosial dan Ekonomi Kehutanan 10(3): 173-185. https://doi.org/10.20886/jpsek.2013.10.3.173-185

10. Safitri, D.I., H. Hinderah, N. Kurniasari, L.S. Akliyah, A.P. Rahardjo, G.M. Maulana, dan T.G. Ramadhan. 2016. Peranan Rencana Tata Ruang Desa dalam Penyusunan APBDes Partisipatif. Ethos (Jurnal Penelitian dan Pengabdian Masyarakat) 4(1): 119-124.

11. Sarkar, R., and A. Sinha. 2015. The village as a social entrepreneur: Balancing conservation and livelihoods. Tourism Management Perspectives 16: 100-106.

https://doi.org/10.1016/j.tmp.2015.07.006 
12. Suhendri. 2014. Pemberdayaan Masyarakat Model Desa Konservasi oleh Balai Taman Nasional Gunung Palung di Desa Sedahan Jaya Kecamatan Sukadana Kabupaten Kayong Utara. Sociodev, Jurnal S-1 Ilmu Sosiatri 4(4).

13. Wahyudi. 2014. Teknik Konservasi Tanah serta Implementasinya pada Lahan Terdegradasi dalam Kawasan Hutan. Jurnal Sains dan Teknologi Lingkungan 6(2): 71-85. https://doi.org/10.20885/jstl.vol6.iss2.art1

14. Yusuf, A.W. 1997. Pranata Pembangunan. Bandung: Universitas Parahyangan. 